\title{
Mississippi Semester: New Social Justice Approach to Teaching Empirical Reasoning in Context
}

Premilla Nadasen

Barnard College, pnadasen@barnard.edu

Fatima Koli

Barnard College, fak2116@columbia.edu

Alisa B. Rod

Barnard College, arod@barnard.edu

David Weiman

Barnard College, dweiman@barnard.edu

Follow this and additional works at: https://digitalcommons.usf.edu/numeracy

Part of the Community-Based Research Commons, Gender and Sexuality Commons, and the Inequality and Stratification Commons

\section{Recommended Citation}

Nadasen, Premilla, Fatima Koli, Alisa B. Rod, and David Weiman. "Mississippi Semester: New Social Justice Approach to Teaching Empirical Reasoning in Context." Numeracy 12, Iss. 1 (2019): Article 3. DOI: https://doi.org/10.5038/1936-4660.12.1.3 


\title{
Mississippi Semester: New Social Justice Approach to Teaching Empirical Reasoning in Context
}

\begin{abstract}
Under the direction of Professor Premilla Nadasen at Barnard College, the course "Mississippi Semester," brings together a small group of undergraduate students in a collaborative action-driven project with Mississippi Low-Income Child-Care Initiative, an advocacy organization of women on welfare and childcare providers, based in Biloxi, MS. Students worked closely with members of Mississippi Low-Income Child-Care Initiative to develop an Economic Security Index for women in Mississippi which the organization will use to educate their constituency and to further their advocacy work.. We have partnered with the Barnard Empirical Reasoning Center to utilize census data and GIS to digitally map the information. We spent seven days in Mississippi to participate in community meetings to get feedback on the economic security index, conduct interviews with residents about their experiences with poverty, and meet with state legislators. Upon returning to New York, students engaged in post-trip recalibration of the index and prepare op-eds for publication. In addition to the history of welfare, students learned survey and interview techniques, GIS mapping, how to write op-eds and will develop a relationship with low-income women. This is an example of how collective community/faculty/student collaboration can equip students with concrete skills and teach them about public policy and community organizing, while simultaneously providing a service to an under-resourced organization. Though this course focused on the state of child care, race relations, economic inequality, and welfare in Mississippi, it offers a new pedagogical approach that can be used as a template for students and educators who desire to engage with contemporary social justice issues. This class flipped the traditional classroom because it was organized around the needs of the community organization rather than an academic research agenda and laid the foundation for a long-term campus-community collaboration. In addition to fostering greater understanding between those inside and outside the academy, it presents a horizontal and collaborative relationship between teacher and students, in which students took charge of and provided leadership around various components of this project. In this way, the course offered multiple approaches to contributing to a social justice agenda.
\end{abstract}

\section{Keywords}

social justice, quantitative data, pedagogy, economic security index

\section{Creative Commons License}

\section{c) (i) (8)}

This work is licensed under a Creative Commons Attribution-Noncommercial 4.0 License

\section{Cover Page Footnote}

Premilla Nadasen, PhD, is a Professor of History at Barnard College. She teaches, researches, and writes about race, gender, social policy, and organizing. She is currently serving as the President of the National Women's Studies Association. Fatima Koli is the Lab Coordinator for the Empirical Reasoning Center at Barnard College and a Master's Data Science student at Columbia University. Her research interests are in racial justice, particularly through the lens of the criminal justice system. She is also interested in ethical data science and methods for teaching students how to think critically with data and maps. Alisa Rod, $\mathrm{PhD}$, is the Associate Director of the Empirical Reasoning Center at Barnard College. She has a background in survey research methodology and her research interests include assessment, numeracy education, and pedagogy. She is currently serving as a board member of the National Numeracy Network. David Weiman, PhD, is the Alena Wels Hirschorn '58 Professor of Economics and Faculty Director of the Empirical Reasoning Center at Barnard College. He specializes in 19th and 20th century U.S. economic 
history, the political economy of contemporary U.S. criminal justice policy, and the history of economic thought. His current research focuses on the evolution of the U.S. banking-monetary system from the demise of the Second Bank of the United States to the founding of the Federal Reserve System. 


\section{Introduction}

Measuring economic security seems simple enough. We are inundated with statistical indices, reports, and quantitative data that gauge the economic status of ordinary people. The Trump administration, for example, points to declining unemployment rates and rapid GDP growth as evidence of a robust economy. ${ }^{1}$ Those who are not so optimistic cite the growing inequality in the distribution of these gains, notably the sluggish growth in median household earnings (adjusted for the rising cost of living) and persistent poverty rates of around 12 percent of the population (Fontenot et al. 2018). Moreover, the United Nations Special Rapporteur on Extreme Poverty and Human Rights reported in 2018 that the number of Americans living in extreme poverty (less than \$2 a day) has doubled over the past 20 years. ${ }^{2}$ Admittedly, determining a useful measure for economic security and nailing down how statistical information reflects the lives of real people is a monumental task.

The difficulty of conceptualizing and measuring poverty became evident through a collaborative teaching and research project at Barnard College. The project involved a campus-community partnership with a Barnard professor of history, the Mississippi Low-Income Child-Care Initiative ${ }^{3}$ (MLICCI) - a Biloxibased advocacy organization of women on welfare and child-care providers - and Barnard's Empirical Reasoning Center (ERC), which assists students in research design and data analysis skills. The partnership took the form of a course, "Mississippi Semester: Child Care, Race, and the History of Welfare," designed to foreground the organization's needs rather than those of the students or professor. MLICCI asked that the students develop a women's economic (in)security index that would aid them in policy formulation. In creating an index, students not only relied on census data and spatial analysis, but also made a site visit to draw on the input and experience of local organizations and stakeholders across the state. The final maps and report illustrate how students' empirical research can be utilized to assist a community organization, shape public policy, and simultaneously cultivate skills that could be utilized in their post-graduate careers.

\footnotetext{
${ }^{1}$ Of course, it is an empirical question whether the president's remarks are intended to reflect or to influence current economic conditions (Wood et al. 2005).

${ }^{2}$ See https://digitallibrary.un.org/record/1629536. The U.S. Census Bureau uses a broader measure of "deep poverty," defined as living in a household whose annual cash income is less than 50 percent of the poverty threshold (in 2016 equal to $\$ 6,243$ for an individual under the age of 65 and $\$ 12,169.50$ for a family of four with two children); see https://poverty.ucdavis.edu/faq/whatdeep-poverty.

3 https://www.mschildcare.org
} 
After an application and interview process, eight students with varying areas of expertise and from different disciplines, including education, history, health sciences, American studies, and journalism, enrolled in the course. It was a racially diverse group. All the students had either personal or organizing experience in lowincome communities. The cost of the course to them was covered by a college grant so that no one was denied participation because of lack of funds. The College also funded the contributions of the ERC staff, whose primary mission is to support these kind of curricular innovations.

The course raised numerous questions for the students about measuring poverty and illustrated how collaboration can reformulate questions and deepen the ways we think about poverty. Equally important, students' hands-on work with data and engagement with a community-based organization created a learning model that many found transformative. This article will document the process of social justice collaboration and make suggestions for how such partnerships can inform our thinking about data analysis, empirical reasoning, and campus-community engagements.

\section{Campus-Community Collaborations}

The course is part of a novel pedagogic experiment at Barnard College that the instructor, Professor Premilla Nadasen, describes as collaborative, communityengaged learning through research and advocacy. She and two of her History Department colleagues, Nara Milanich and Abosede George, have proposed a curricular model they are calling the Community Engagement Initiative. In this experiential learning model, students develop academic knowledge and skills in the context of close collaborations with grassroots and social justice organizations. Through involvement with these projects, students learn about pressing policy and social justice issues and hone a variety of practical skills that will prepare them for citizenship, leadership, and advocacy.

Although community-engaged learning is practiced at other institutions, the particular combination of experiential learning, centering the needs of an underresourced community organization, a commitment to long-term collaboration, and the collective nature of the classroom experience is somewhat unusual. Mississippi Semester, the pilot course for this initiative, reflects this pedagogical approach that bridges campus and community and introduces students to new ways of thinking. The goal in working with MLICCI was to flip the typical script of campuscommunity projects and engage with Mississippi residents as research partners rather than as research subjects.

Nadasen had worked with MLICCI for a few years. She first learned of them through the Ms. Foundation's Economic Justice Program, which funds grassroots organizations. In December 2016, she was invited by MLICCI to speak before the 
Mississippi Women's Economic Security Summit. During that visit, MLICCI Executive Director Carol Burnett discussed the organization's need for research and data collection, inquiring about a possible collaboration with Barnard College. Producing research has been part of MLICCI's larger strategy to draw attention to women's economic insecurity and to develop a legislative agenda that could influence how the state allocates Temporary Assistance to Needy Families (TANF) funds. Nadasen, a qualitative historian whose research has centered on narrative and storytelling of welfare recipients and domestic workers, agreed, with some trepidation.

She turned for assistance to Professor David Weiman, Director of the Empirical Reasoning Center. The ensuing project, funded by a Barnard College Innovation in Teaching Grant, involved bridging ostensibly divergent methodologies: qualitative and quantitative research on poverty, often rooted in different literatures. What they found is that although they sometimes spoke different academic languages (for example, Nadasen used the term intersectionality and Weiman talked about cross-correlation) in fact the goal was the same: to illustrate the complexity and nuanced nature of poverty as it intersects with race, gender, disability, family status, and other factors. In order to convey the complexity of this topic to the students during the empirical training, Alisa Rod, ERC Associate Director, and Fatima Koli, then ERC Graduate Lab Fellow, developed a set of learning goals to guide the structure and number of workshops. During the workshops, Koli taught students to: 1) choose a set of indicators, 2) use GIS to map indicators and use Excel to develop a composite index, 3) solicit strategic feedback from community stakeholders on their data analysis, and 4) based on community input, recalibrate their maps and indices.

The course was a model of hands-on learning in which students developed a set of practical skills, worked with a community organization, and contributed to the development of an operational social policy tool. The methodological approach combined reading and discussion of secondary historical and theoretical texts in the classroom, engagement with quantitative-spatial empirical reasoning in the computer lab, and participation in open-ended discourse with community organizations on site. Students found that both quantitative and qualitative data, as well as input from community partners, were essential for an adequate assessment of economic security and a fuller picture of what economic security means for Mississippi residents.

\section{What Is Economic (In)Security?}

Reflecting the inherent complexity of the subject matter, the course draws on three distinct, though related, literatures on how to measure economic insecurity or poverty. The first two rely on the policy "expert" to specify what constitutes a 
minimally sufficient living standard and corresponding metrics to gauge who has sufficient resources to "get by." The two differ, however, in how they conceive of this "living" wage, and hence the scope and magnitude of the minimum sufficient household budget. The alternative "capabilities" approach shuns any attempt to specify this bundle of goods and services a priori, and instead emphasizes essential capabilities for household members to realize their ends, including a decent living standard but also a meaningful and fulfilling life in their communities. Consequently, it is inherently contextual, relying on the lived experiences of members of a population and their input in specifying their particular requisites for a good life and (conversely) the impediments that they confront to achieve it.

\section{The Official Poverty Threshold}

The official poverty threshold has its origins in the Social Security Administration, which in the early 1960s faced an expanded mandate to provide assistance to "economically insecure" families, not just children (corresponding to the change in name of the original program from Aid to Dependent Children to Aid to Families with Dependent Children). ${ }^{4}$ By economic insecurity, the research analyst primarily responsible for the current measure, Mollie Orshansky, sought a minimum income level or cut-off point, below which household members would clearly suffer deprivation (for example, parents foregoing nutritious meals in order to feed their children, or likewise for elderly adults to tradeoff medications for nutrition; see Neckerman et al. 2016). Expressed colloquially, this income level would be sufficient for households to, in Orshansky's words, just "get-along."

Recognizing the challenge of specifying this essential bundle of goods, especially non-food items, Orshansky instead built her estimate on two readily obtainable and reasonably reliable empirical parameters: (1) Department of Agriculture (DoA) estimates of the food budget of low-income households (in the bottom third of the income distribution) and (2) estimates of the Engel's law relationship. To meet the just "get-along" criterion, Orshansky selected the DoA "economy" food plan. Set at approximately three-quarters of the "basic low-cost [income]" budget, it would suffice during an emergency, when households suffered a temporary, sharp drop in income (Fisher 1997). Engel's law traced the relationship between households' food expenditures and their disposable income. At the time, it implied that low-income households devoted around onethird of their after-tax incomes to food purchases, which yielded a multiplier of three. In other words, her temporary, emergency level of disposable or after-tax income equaled three times the "economy" food budget.

\footnotetext{
${ }^{4}$ See Fisher $(1997,8)$. For a brief history of these programs authorized under Title IV of the 1935 Social Security Act, see Gordon and Batlan (2011).
} 
Her initial estimate, released in 1963 and subsequently revised and refined in 1964 , was $\$ 3,165$ for a family of four (in 1962 dollars or the equivalent of $\$ 25,600$ today). Its release coincided with the announcement of President Johnson's "War on Poverty" initiative, and served as one rationale for the administration's official poverty threshold (of $\$ 3,000$ ) and an estimated poverty rate of nearly one-fifth of all households. As explained in the Council of Economic Advisers' (CEA) Economic Report of the President, households were counted among the poor if they lacked sufficient resources to meet the poverty income threshold (U.S. President 1964). The Economic Report acknowledged the empirical challenges in estimating household resources and opted for the census data on money income despite its obvious limitations. In particular, the census variable measured pre-tax income and so overstated households' available or disposable income to purchase the minimum threshold consumption bundle.

The early debates over an official poverty threshold also raised the critical question of how or if it should be adjusted over time. Researchers recognized the obvious critique of an "absolute" standard such as Orshansky's based on food budgets and multipliers in the late 1950s. An "appropriate poverty measure in 1900 or 1933," Orshansky's "boss" observed, would not be a "relevant standard" in the mid-1960s (Fisher 1997, 13). A "relative" standard, by contrast, would peg the poverty threshold to changes in overall living conditions. At the time Orshansky's measure actually met one commonly proposed relative standard, equal to "onehalf" of median household income (Smeeding 2017).

Pivotal officials (notably in the Bureau of the Budget and the CEA) rejected this alternative of periodic revisions based on a moving target, despite its logic and simplicity (Fisher 1997). Precisely because the official rate had become assimilated into federal poverty programs, they worried that large changes in the poverty thresholds would confound their rules and regulations and in turn significantly increase program outlays (National Research Council 1995). Meanwhile, CEA members raised the decidedly political concern about "score-keeping," as the poverty measure had also become a metric to assess the impact of War on Poverty programs. Consequently, all sides reached a consensus to maintain the real value of the original threshold by adjusting it to keep pace with changes in the Consumer Price Index.

\section{From a Poverty to a Self-sufficiency Index}

As recognized at the time, the official poverty measures were built on shaky empirical and conceptual foundations. Orshansky, for one, acknowledged that her estimates relied on already dated benchmarks of food outlays and shares (hence multipliers). Moreover, they did not incorporate necessary tax payments to render them comparable to the disposable income data used to measure household resources. At a more fundamental level, Orshansky constructed an "emergency" 
budget, applicable to (for example) households experiencing a bout of short-term cyclical or frictional unemployment. It did not match her overarching concern to gauge their "relative risk of low income status." She rationalized this decision to understate poverty thresholds on the grounds that she could more confidently figure out "how much is too little," rather than "how much is enough" (quoted in Fisher 1997, 5).

The weaknesses of the official poverty threshold were also not lost on community and grass-roots anti-poverty groups. Welfare rights activists in the 1960s, for example, relied on the federal poverty threshold to expose the insufficiencies of family welfare budgets. But they also sought to formulate an expanded definition of need that went beyond Orshansky's deprivation benchmark. They advocated a relative standard - one which included money for things such as summer camp for their children, winter clothing, and a telephonethat aligned more closely with the capabilities framework and would have provided them and their children an opportunity to realize a full and meaningful life (Sen 1999, 2009; Robeyns 2016). In this vein, in 1968, the National Welfare Rights Organization proposed a guaranteed annual income of $\$ 5500$ for a family of four. Although introduced into Congress, the bill never made it to the floor (Nadasen 2005). Nevertheless, their participation in this debate illustrates how those individuals most directly impacted can devise a more applicable concept of need and economic security.

To correct defects on the resources side of the equation, the Census in 1982 constructed and published an "experimental" poverty measure based on households' estimated disposable income rather than their total earnings. Then, in the early 1990s Congress asked the National Research Council (NRC) to convene a study panel that would systematically diagnose the official policy measure and recommend revisions to place it on a sounder footing for policy-making, program administration, and research (NRC 1995). The panel adopted Orshansky's conceptual approach, conceiving economic insecurity as a state of "economic" or "material" deprivation-when households' total resources could not meet their expenditures on "basic living needs" (NRC 1995, 19-21; Smeeding 2017, 22). It also followed her empirical strategy, though with more realistic estimates of households' truly disposable resources, their core needs for food but also housingutilities and clothing, and finally a more current expenditure multiplier to cover other items.

The panel's volume, Measuring Poverty (NRC 1995), clearly spelled out the limitations of the official measure and their recommendations to remedy them. On the resources side, for example, it endorsed the current experimental measure that deducted net taxes (taxes minus transfer payments) while recommending the deduction of other necessary (or in the panel's words, "non-discretionary") expenditures for working adults (and especially parents)—notably commuting 
costs, childcare services including payments to other families, and outlays for medical care and insurance (net of any private and public benefits). The first two items in particular had become increasingly burdensome for low-income households because of the relocation of potential jobs to more distant, suburban and exurban sites and the increasing labor force participation rates of adult women with children, whether in single- or two-parent families. (Regarding the spatial mismatch between the residential location of and the job opportunities for poor especially minority households, see Raphael and Stoll 2002).

On the expenditure side, the panel elaborated Orshansky's multiplier approach. It broadened the notion of basic living needs to cover housing-utility and clothing expenditures and lowered the multiplier accordingly (from 3 to 1.15 to 1.25) to cover the reduced list of "other" items. Additionally, the panel recommended regular adjustments to household expenditures to compensate for variations in living conditions over space and time. Unlike in the official measure, the panel recommended regional thresholds to incorporate often large differences in housing costs. And besides cost of living adjustments, it recommended a quasirelative standard that would incorporate changes in overall living standards. All told, these changes increased poverty thresholds marginally, by about 7 percent in 2016 (to $\$ 26.1$ thousand for a family of four as compared to the official poverty threshold of $\$ 24.3$ thousand).

Despite its critique of "expert" budgeting, the panel's recommendation approximated thresholds based on this methodology. After all, unlike the official measure, its "supplemental" estimates of households' basic needs accounted for nearly 90 percent (versus only one-third) of the proposed poverty thresholds. This initiative, not surprisingly then, formed the basis of more recent attempts to derive "self-sufficiency" indices that more completely measure what it takes to "getalong" in a particular place and at particular time. Eschewing the multiplier approach, these indices explicitly take into account other necessary expenditures on items such as "personal care supplies and services," "housekeeping supplies," education, and basic telecommunications services (Glasmeier and Nadeau 2017, 69; Kimberlin and Rose 2017, 73). Several also extend the notion of self-sufficiency to include "economic security" provisions (see for example Kimberlin and Rose 2017, 5). These indices would include sufficient income above necessary expenses for precautionary savings to meet "unexpected emergencies" but also "life-cycle" savings to pay for additional education and training to qualify for good jobs - with lower turnover, higher pay, opportunities for advancement-and retirement. Needless to say, the latter are the most generous yielding a "living wage" (without any government assistance) of just over $\$ 50$ thousand in (disposable) income for a family of four in the New York metropolitan area, more than twice the "official" poverty level. 


\section{The Capabilities Approach}

Researchers taking the Census Administration poverty threshold or material deprivation approach have recognized an alternative way of conceiving an economic security index. Instead of gauging whether or not households currently have sufficient resources to meet their basic needs (including perhaps a surplus for "necessary" savings), they consider whether households, individually and collectively, have the basic capabilities to secure a "living wage" and more broadly to realize their life chances including their full participation in their communities (see for example Smeeding 2017). These factors range from access to good schools and jobs, locally or within reach by efficient, low-cost transport services, to effective civil rights enforcement obviating gender and racial discrimination.

A study by the New York Women's Foundation (2013; for the underlying technical analysis, see Pearce 2010) explicitly adopts this kind of multidimensional approach. Its economic security sub-index, for example, gauges the extent of deprivation among households and communities by common indicators such as poverty rates and median earnings. At the same time, it also identifies (albeit imperfectly) the community conditions that enhance the employment opportunities of household members in terms of median wages and unemployment rates. Additionally, it includes indices to measure educational opportunities, access to healthcare, and safety (as measured by, for example, rates of infant mortality, health insurance coverage, and sexual violence).

Conceptually, this alternative approach derives from Amartya Sen's capabilities theory of individual freedom (Sen 1999, 2009; see also Alkire 2007 and Robeyns 2016). In contrast to the poverty or self-sufficiency threshold approaches, Sen gauges individuals' or households' economic security in terms of their real opportunities to live a "good" life - that is, to pursue and realize their own life plans. Material sufficiency may be a necessary ingredient in this mix, but cannot insure households against abrupt economic and political changes that can undermine their well-being. Sen's challenge, then, is to identify the essential resources that will enable the affected individuals or households to fully recover and resume their lives on a secure footing. Besides its more dynamic view, his theory also avoids a common critique of self-sufficiency indices, which only rely on a priori "expert" judgements to devise "ideal" household consumption bundles and corresponding income levels. Sen would also include the input of the affected population to ensure that they have the necessary means to exercise their autonomy.

Empirical researchers have translated Sen's theory into multidimensional poverty indices, along the lines of the New York City study (see for example Alkire 2007 and Glassman 2017). Multidimensional poverty incorporates standard measures of household economic or material deprivation (such as a household's relative poverty), as well as the many essential conditions that either enhance or impede individual "functionings" and collective action (e.g., educational levels and 
opportunities, health status and healthcare access, social networks and capital but also pervasive social disorder, political disenfranchisement, etc.). Advocates of this multidimensional approach have also specified several criteria for narrowing down what is potentially an unending list of possible dimensions and devising a meaningful array of weights to assign to each item. Despite the obvious pragmatic factor of data availability, they have developed a method consistent with Sen's emphasis on human agency. Instead of relying on expert judgements, these researchers insist on giving voice to "the people involved" to reach a genuine consensus through their ongoing deliberations. The challenge, then, is to devise a "legitimate" mechanism to specify the relevant dimensions and the weights given to each (Alkire 2008, 102).

\section{Into the Classroom: Interrogating the Alternative Notions of Economic Security}

Students considered these multiple ways of conceptualizing poverty and grappled with the distinctions among extreme poverty, poverty, economic security, a living wage, and well-being. They discussed how the Women's Well-Being Index produced by the California Budget and Policy Center and the Economic Security and Well-Being Index for Women in New York City by the New York Women's Foundation may or may not provide templates. The health sciences major, for example, proposed including access to the Children's Health Insurance Program (CHIP) as one factor lifting families out of poverty. The education major argued that early childhood education was foundational for economic success, while the American studies and history majors raised potential barriers to economic security, such as criminalization, police harassment, and disability. They rejected a singular measure of income because it would not capture multiple household resources or needs. In consultation with MLICCI, they decided that their goal would be to try to assess economic security (which considers factors such as education and child care availability) rather than well-being (which more broadly calculated such factors as political participation and freedom from gender-based violence).

The professor, students, and ERC Fellow brainstormed possible criteria by which to measure economic security. The result was their a priori "expert" judgement based on an overview of the available data. They generated a long list, reflecting the students' understanding of the multifaceted nature of poverty. It included earnings, unemployment rate, public assistance, poverty rate, child care costs, education, health insurance, work experience, housing costs, disability, family size/status, and household living arrangements. They struggled to narrow down the salient factors into a manageable number and sought to determine which factors may be captured in other indices. In choosing indicators and developing an 
index, they encountered a number of tensions and had to make a series of compromises.

Importantly, they were committed to developing an intersectional analysis of poverty in Mississippi - that is, thinking about not just the significance of race or gender as separate variables, but how economic status is differentiated by race among women and men. This perspective is especially important because neither race nor gender alone can account for economic inequality. Their agreement on this issue is likely a product of the broad conversations about intersectionality on the Barnard College campus and also the interview and screening process by the professor who sought out students who were interested in both race and gender. Since its founding in 1998, MLICCI had lobbied for and organized around women's issues and had studied how diminishing welfare assistance in the state had adversely affected women's well-being, particularly that of black women. As a study by the U.S Commission on Civil Rights concluded in 2016, racialized practices in the disbursement of TANF and child care assistance continue to disadvantage black women in Mississippi. ${ }^{5}$ The long history of racial inequality and patterns of systemic and institutionalized discrimination meant that black Mississippians fared far worse economically than white Mississippians. Consequently, the goal of the index was to capture the racialized and gendered character of poverty.

Students read historical and theoretical texts that grounded them in welfare history and the Mississippi context, including Dorothy Roberts' Killing the Black Body: Race, Reproduction and the Meaning of Liberty, Crystal Sanders' A Chance for Change: Head Start and Mississippi's Black Freedom Struggle, Kaaryn Gustafson's Cheating Welfare: Public Assistance and the Criminalization of Poverty, and portions of Clyde Woods' Development Arrested: The Blues and Plantation Power in the Mississippi Delta. These readings, along with research about contemporary poverty and welfare policy, gave students a framework to consider the specific case study and theoretical tools to construct a racialized and gendered index of poverty in Mississippi.

Although students encountered the persistent problem of whether to measure deprivation, self-sufficiency, or capability, it was clear that this problem could not be resolved until we had some input from those people (e.g. child care providers and economically insecure women in Mississippi) who are most directly affected. This resolution would only be fully realized with the trip to Mississippi and our collaboration with MLICCI, described later in the paper.

\footnotetext{
${ }^{5}$ http://www.usccr.gov/press/2016/PR_LettertoHHSonLow-IncomeChildCare.pdf.
} 


\section{Into the Classroom: Measuring Economic Security}

With the assistance of Koli, students in this course were expected to develop an understanding of how to construct and critique a numerical index. Koli took responsibility for advising the students, who had limited experience with data analysis and statistics, and finding and cleaning the data at the beginning of the semester prior to the workshops. In addition to brainstorming relevant indicators, students had to take into account the availability and accessibility of the quantitative evidence or data.

As students determined which economic security indicators to include, Koli looked into possible data sources that could be utilized to construct the corresponding index. A key source for data was the American Community Survey (ACS), a survey conducted by the US Census which asks questions about housing, educational attainment, income, language, employment, race, gender, and other key factors and is available at varying geographic levels (e.g., county). The ACS collects data annually and thus has more recent information than the decennial Census. Finding detailed data on variables such as disability, child care costs, and public assistance was more challenging because the ACS either does not incorporate many of these items or in cases where some data exist, access was limited. Taken together, the time constraint of needing to complete the project by the end of the semester and the limitations of ACS data resulted in students choosing five variables.

The data were available in various forms, each of which posed trade-offs between the level of detail, the geographic scale, and the time available. The ACS releases data in aggregated one-year estimates, aggregated five-year estimates, and a Public Use Microdata Sample (PUMS). The one-year estimates are more recent, but are prone to larger standard errors and are generally at larger geographic scales (e.g., the state level). The five-year estimates have lower standard errors and are available at smaller geographic scales (e.g., by county or census tract). The PUMS is not aggregated, and contains the response to every question from a sample of respondents. These data are useful when trying to create custom cross-tabulations, because the one- and five-year alternatives are only calculated for specific variables. Because they raise obvious privacy concerns, the PUMS data are only available at the Public Use Microdata Area (PUMA) geographic scale. These PUMAs were significantly larger than counties for Mississippi, with the whole state having a total of 21 PUMAs versus 82 counties.

The lack of available data at an appropriate unit of analysis was one of our primary challenges. We wanted to have access to detailed data on individuals in order to understand the multifaceted nature of economic security, but we also wanted to understand economic security at a more local geographic level. As a compromise, we chose in the end the five-year ACS estimates. We would not have 
detailed information for each individual, but we would be able to analyze the data for most variables by race and gender, which was a priority for both MLICCI and the class.

Some key variables for our index, such as the living wage index and child care costs, posed data challenges and were excluded from our analysis. Students wanted to include a living wage index to emphasize the notion that families need more than just the bare minimum (i.e., the poverty threshold) to get by. The Living Wage Calculator does provide estimates at the county level, but only based on family characteristics, which were incompatible with our more aggregated ACS data. Because child care costs vary widely across individuals and communities, they could not be simply aggregated into a meaningful index. The data for child care costs were also not readily available and could not be estimated through any proxy variable.

Our data set did include health insurance, though these data were only aggregated by race and gender separately, but not by the combination of the two. Lastly, we considered four demographic groups: black men, black women, white men, and white women. The sex variable was limited to these two categories, because the census only provides those two options. We also limited the race variable, choosing only black and white, which covers approximately 96.5 percent of Mississippi residents. We didn't include other racial-ethnic categories because the number of observations for those categories were generally small and resulted in high standard errors for the estimated values.

\section{Applying Empirical Reasoning in Context: Stage 1}

We knew teaching a highly quantitative course to students with backgrounds in qualitative research would pose certain challenges. Students unfamiliar with interpreting data would be introduced to both quantitative thinking and the software applications needed to perform the analysis and to effectively visualize their results. We decided to hold four workshops for the students (faculty were not present) outside of the regularly scheduled class meeting time throughout the semester. The workshops would briefly cover all of these aspects of quantitative empirical analysis, with a strong focus on performing the calculations in Excel and mapping the results in QGIS.

Our goal for the workshops was to introduce students gradually to the process of working with quantitative data. The first workshop focused on SocialExplorer, an online tool for mapping US Census and ACS data. ${ }^{6}$ SocialExplorer has an intuitive user interface and allows users to explore data interactively. In this manner, students were able to look at visual relationships and practice interpreting

${ }^{6}$ www.socialexplorer.com 
them rather than calculate variables or make the maps themselves. SocialExplorer could not be used to map our index, but did give the students an example of what to aim for regarding our final visualizations.

The second workshop centered on how to use a spreadsheet application, in this case Excel, to create an index. Since we had not finalized the list of indicators by this point, we instead chose several example variables (employment and health insurance), which were relevant in the context of an economic security index. We limited our workshop example indicators to a few variables so that we could deconstruct the steps in calculating an index and avoid using the time to continue the ongoing class debate about selecting indicators. For this reason, we also cleaned the data for them beforehand by removing missing values, aggregating data for the genders by age, and calculating percentages for the data. Data cleaning is often one of the most difficult challenges in any quantitative project, and we wanted students to focus on learning the tools that they would need to calculate an index and create map visualizations. Although data cleaning is an important skill with regard to working with quantitative data, due to the limited time, we determined that this preprocessing step was outside the scope of the goals for the empirical training for this course. During this workshop, the students learned how to construct equations, reference cells, and normalize data. They normalized each variable and then rescaled them so that the revised variables would range from 0 to 100 . In this simple exercise, students calculated an index value for each county, equal to the simple average of the constituent variables.

The first two workshops were held before the site visit to Mississippi to prepare students for their trip. During the trip, they gathered qualitative data to inform the indicators for the index and the weights given to these indicators. The third workshop consisted of recalculating the index with the final list of indicators. We imagined that students would need a refresher on some of the elements covered in the second workshop, so the third workshop was designed to be similar in nature and go through the steps again. The only difference between the second and third workshop was the development of the final list of indicators and the application of the weights to the indicators. The fourth (and last) workshop introduced the final quantitative element of the class - mapping in QGIS - and helped students map the index that they had developed in the third workshop. We discuss the third and fourth workshop in further detail following the section in this paper on the site visit to Mississippi.

Throughout these workshops, students were taught to think critically about data and maps and what each of these components might represent. This was done through examples of misleading maps and by considering how decisions are made in the process of developing a map. Students were taught that maps are simply constructs and so are based on the assumptions, possibly biased, of the mapmaker and of the viewer. Although seemingly obvious, maps and data are often read as 
objective. We wanted students to question that and realize that biases are inherent in various empirical analyses. For example, we considered a map that represents the number of Black individuals across the counties in the state of Mississippi. As we looked at a comparable map for white individuals in the state, students noticed some similar spatial patterns and were confused by the seeming overlap between the two distributions (Fig. 1). While the maps accurately reflected the data, they did not necessarily tell us about racial differences in the spatial distribution of communities. That is because both maps were displaying visualizations of raw frequencies, which reflect the geographical concentration of people in cities and towns. Instead, we wanted the maps to show which areas had a larger representation of Black individuals relative to the total population. Thus, students were then shown a map visualizing this information normalized by the total population and represented as percentages (Fig. 2). Designing an activity centered around a discussion of the process of questioning patterns and thinking about what the numbers meant reinforced critical thinking skills related to maps and data.
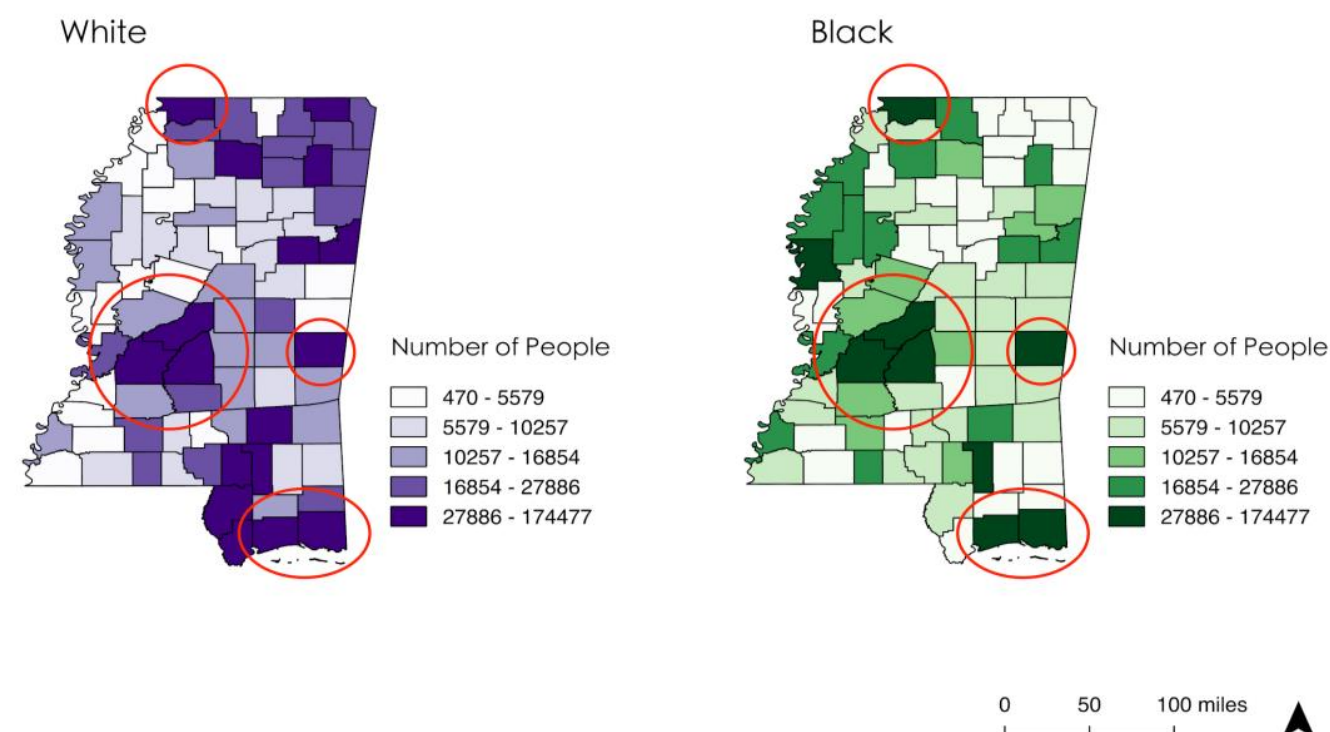

Figure 1. Population by race by county in Mississippi 
White

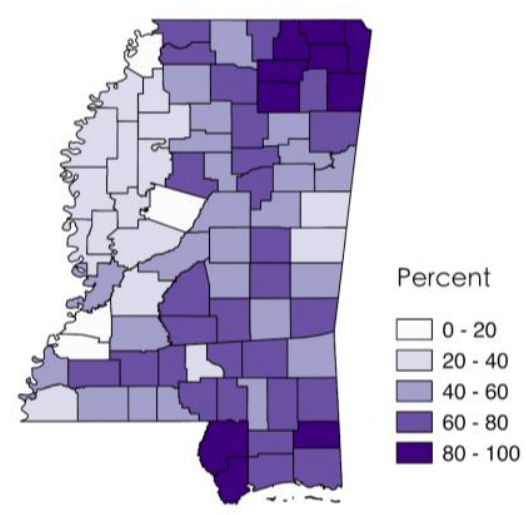

Black

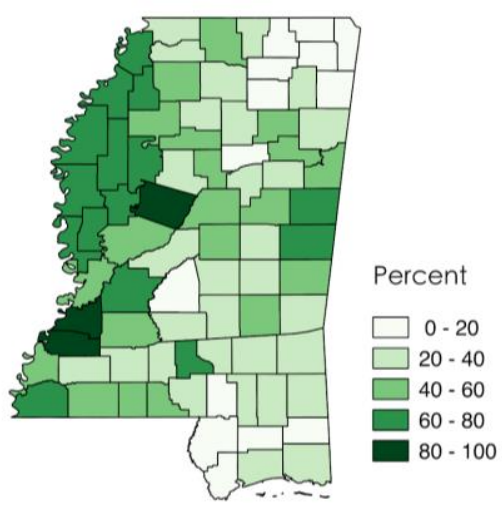

$0 \quad 50 \quad 100$ miles

Figure 2. Percent of population by race by county in Mississippi

Based on the most readily available data and time constraints, students chose eight preliminary indicators: median earnings, unemployment rate, percent of women in poverty, percent of children in poverty, percent of women in low-wage occupations, educational attainment, the gap between public assistance eligibility and receipt, and percent of women with health insurance. The next step was to hear from Mississippi residents regarding their prioritization of these dimensions of economic security (i.e., how to weight the indicators) and whether there were important indicators missing from our list.

\section{Site Visit: Poverty on the Ground}

With the historical background and statistical analysis in hand, the students embarked on a week-long field study during spring break to enrich their understanding of the actual experiences and expressed needs of Mississippi residents. ${ }^{7}$ Students were charged with getting feedback on the preliminary index

\footnotetext{
${ }^{7}$ Costs were covered by Barnard College (through funds from a private grant for innovative teaching). Planning for the trip included securing accommodations and organizing meals and transportation, all of which were done by the faculty member. MLICCI assisted with planning the itinerary and setting up meetings with local stakeholders. Students also kept up with current events in Mississippi, conducted practice peer interviews, and discussed rules of engagement with community members. They worked in teams to help carry out some aspects of the course, such as setting up the website, collecting relevant news articles, and doing background research for the index. Although this project entailed a site visit to another state, a similar project could be developed with a local community organization.
} 
from various stakeholders in Mississippi. They met with low-income child care providers, unemployed mothers in a job training program, and representatives of advocacy groups such as Teen Health, the Mississippi Coalition Against Domestic Violence, and the Mississippi Community College Board. They collected additional qualitative data through focus groups and informal interviews, which alerted them to aspects related to poverty that they had not previously discussed or were not included in the preliminary list of indicators. The students learned, for example, about the inadequate public transportation system in both urban and rural areas that imposed barriers to employment. They also heard stories of health and disability that hindered people's capacity to work and navigate easily through their daily lives. In addition, a number of respondents discussed the problem of debt as a primary obstacle to economic security. One of the most illuminating conversations about economic security occurred during a conversation with women in a job training program. When asked what they would do if they were economically secure, they suggested they would focus on community improvement (e.g., fixing up a local playground, opening up a youth center, and helping out their neighbors), rather than just individual well-being.

Our original intention was to use this additional information to critically assess and recalibrate our original measures of economic security. However, both the constraint of time in a semester-long project and the lack of available data aggregated by race and gender rendered it infeasible to fully incorporate the feedback during this course.

\section{Applying Empirical Reasoning in Context: Stage 2}

Upon returning from the trip, students attended two additional workshops in order to prepare themselves to calculate the final index and create map visualizations of the indicators. Prior to the semester, we had assumed that following the trip we would determine the final indicators and the corresponding weighting scheme and thus would be prepared to calculate the index. However, the qualitative data gathered during the trip demonstrated that there were new factors we had to consider, which complicated our initial planned timeline. Additionally, it was difficult to decide how to best incorporate an intersectional approach to the index. We postponed the calculation of the index and instead decided to teach mapping in the third workshop.

During the third workshop, we focused on teaching introductory QGIS and showed students how to create choropleth maps for a single indicator (for example, poverty). Students created four different maps, one for each key demographic group (Fig. 3). Students were taught how to choose appropriate class sizes for legends to ensure maps could be compared across demographics. They were then assigned to 
work in pairs to map indicators, delineating, where possible, populations by the race and gender.

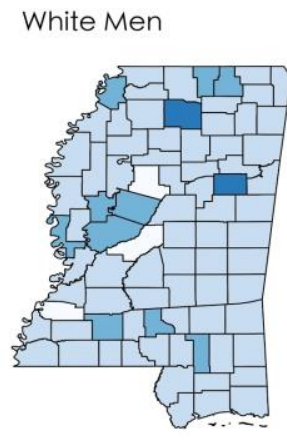

Black Men

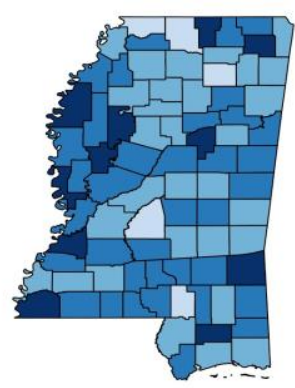

White Women
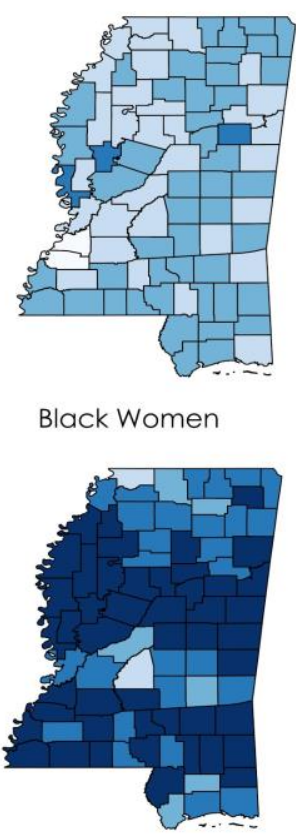

Percent with Income Below Poverty Level
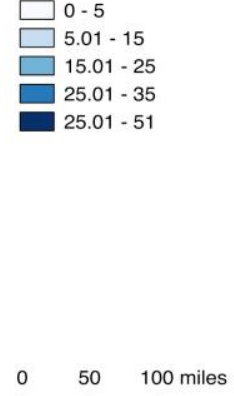

Figure 3. Percent of people in poverty by county in Mississippi across four demographic groups

Prior to the fourth workshop, students were tasked with making a final decision regarding the indicators. The students chose five indicators: median earnings, poverty, educational attainment, access to health insurance, and the unemployment rate. Although not included in the index, students also chose a sixth variable, childcare, to be mapped and analyzed. The five indicators were readily available through ACS and childcare data was obtained from MLICCI.

Finally, in the fourth workshop, students learned how to incorporate the data into a composite index and construct a single index value for each county by race (i.e., each county had two values, one for white women and one for black women). While they mastered the techniques involved, they found it difficult to accept the result for conceptual reasons. They had expected to develop an index that would allow intergroup comparisons and would be readily interpretable in real-world terms, such as the percentage of people who are economically secure in a region. From their perspective, the index "oversimplified" economic insecurity by 
obscuring the rich variation in conditions within counties, as is evident in the varied county rankings based on each individual indicator.

Moreover, the resulting index could only measure the relative standing of each county in terms of the greater or lesser economic security of the particular group. For example, the index value for black women only compared their economic security relative to black women in other counties. It could not show, however, the relative standing of black versus white women within counties, nor could it indicate whether the women in each county, black or white, enjoyed a sufficient living standard. One student in the course, Janice Ko, summarized this viewpoint accordingly in the final report produced by the class for MLICCI (Ko et al. 2018):

An index is, at its core, an abstraction, a flattening tool. It takes as input a spreadsheet of different social indicators and returns to us a single normalized list of counties ranked from "most" to "least" economically secure. Throughout the semester we struggled as a class to hold all of the stories that the data does not capture. Even as we settled on our five indicators, we found powerful counternarratives that complicated the importance we placed on each one.

Although the class was unable to take into account all of what we learned in the workshops, the on-site learning experience laid the foundation for future refinement of the index and prompted discussion about ways to integrate personal narratives alongside the statistical data.

In this manner, over the course of four workshops, we were able to cover the following topics: 1) understanding and working with data, 2) creating data visualizations, 3) developing and interpreting an index, and to accomplish the first three, 4) using Excel and 5) QGIS. Based on our experience, however, we would recommend that courses such as these limit the number of topics introduced to students to perhaps only one or two. If instructors choose more than two, we recommend having mandatory weekly lab sections so that students would have more time and cover each element of each topic more thoroughly. Students found it challenging to grasp all the material in the time span of the workshops. They struggled with the very notion of a composite index and were also confused by the analysis needed for it so we spent considerable time reviewing concepts outside of the workshop.

However, working intensively with quantitative data enabled students to consider the spatial politics of poverty and to think critically about what information quantitative data can convey. In addition, the site visit helped them contextualize the empirical information and analyses. As part of the site visit, they learned that community input was necessary regarding considerations on how to weight indicators and that quantitative data do not convey a complete understanding of an individual's or community's struggle with economic insecurity. For example, the data and mapping exercises clearly showed that the Delta area of Mississippi is one of the poorest parts of the state. But hearing first-hand from a community 
representative that individuals had to travel three hours each way by bus in order to be employed in one of the few factories in the area illuminated for the students the importance of integrating personal experience with spatial data analysis. Transportation was not just a cost issue, but a time factor. Without realizing it at the time, students became aware of the need to employ Sen's capabilities approach to conceptualizing poverty - an approach that centers agency and autonomy and understands the limitations of a priori expert judgments. Students' post-trip reflections acknowledged that we (as "experts") didn't fully grasp the character or depth of poverty in Mississippi. The input of affected individuals is not only significant because it moves us closer to a more accurate measure of economic (in)security but also because the crux of the measure is to represent the individuals involved on the ground in Mississippi, which is only partially captured in a numerical index.

The class decided at the conclusion of the trip that a survey should be conducted to solicit community members' perspectives about poverty. Students came away with a clear sense of the need to probe into the underlying causes of these women's precarious conditions, such as domestic violence, debt, transportation, punitive criminal justice policies, and de facto segregation, among others. At the end of the semester, students combined their quantitative and discursive analyses into a compelling, albeit incomplete, overview that provided MLICCI members with a tool for advocacy work that could be built upon with future projects.

\section{Conclusions and Continued Collaborations}

Students left Mississippi with a keen sense of the value of community partnerships for any assessment of poverty. The individuals and organizations they encountered dominated their informal conversations, subsequent discussions about how to assess poverty, and the personal reflective essays they wrote at the end of the semester. Large-scale data, while critical for providing an overall picture and charting trends over time, does not always convey the nuances of individual lives. The need to produce a tangible deliverable by the end of the semester, with the guidance of the organization and based on their on-site conversations, resulted in students selecting five important (but not exhaustive) indicators and mapping those by race and gender. The breakdown by race and gender for each indicator, missing in many statistical reports, provided a stark picture of racial and gender inequality in Mississippi.

But this course, the report, and the data produced were just a beginning. The Community Engagement Initiative is intended to foster long-term partnerships. MLICCI is continuing to work with the ERC to develop an interactive web map that will allow stakeholders and community members in Mississippi to 
investigate the regional and individual aspects of poverty. The ERC's undergraduate fellows working on the index will ultimately develop a weighting scheme of the indicators based on follow-up qualitative research such as additional focus groups. Students suggested combining quantitative and qualitative data in order to generate a more holistic view of poverty. When the Mississippi Semester course is taught again in the spring of 2019, a new group of students will develop and distribute a survey with additional Mississippi-specific quantitative measures and qualitative information to collect a more detailed and comprehensive portrait of poverty from the ground up.

The index and poverty indicators that emerged from this project are far from comprehensive in comparison to the students' initial list and all the possible factors that may contribute to economic insecurity. The students' final report is a preliminary account of a nuanced and complicated issue, and students ended the semester with more questions than answers. They supplemented the maps with descriptive and analytical paragraphs in the report, and also wrote a blog for the course website. ${ }^{8}$ The blog offers a more textured perspective about the impact of the site visit. Because of the field study, they came away with insights into poverty and welfare policy that could never be acquired in the classroom alone. Equally significant is that the process was a collective effort. Students worked together and, unlike in courses where students develop individual projects or even compete against one another, the entire class-students, ERC grad fellow, and professor - all contributed to a single end product.

In addition to creating a website and publishing a booklet, the class organized a panel discussion about the course at Barnard College at the end of the semester and presented their findings at the annual National Women's Studies Association conference in November 2018. Students conducted an empirical investigation of real value to an organization at the forefront of anti-poverty efforts in the poorest state in the country. In the end, they developed an appreciation for how combining discussion around the seminar table (critical engagement with a body of academic scholarship), work done in a computer lab (the development of a set of empirical reasoning skills), and community input can contribute to collaborative solutions to urgent social problems.

\section{References}

Alkire, Sabina. 2007. "Choosing Dimensions: The Capability Approach and Multidimensional Poverty." In The Many Dimensions of Poverty, edited by N. Kakwani and J. Silber J, 89-119. London: Palgrave Macmillan UK. https://doi.org/10.1057/9780230592407_6.

\footnotetext{
${ }^{8}$ https://mssemester.wordpress.com/
} 
Crosby, Emilye. 2005. A Little Taste of Freedom: The Black Freedom Struggle in Claiborne County, Mississippi. Chapel Hill, NC: University of North Carolina Press. https://doi.org/10.5149/uncp/9780807856383.

Fisher, Gordon M. 1992. "The Development and History of Poverty Thresholds." Social Security Bulletin 55 (4): 3-14.

Fisher, Gordon M. 1997. "The Development of the Orshansky Poverty Thresholds and Their Subsequent History as the Official U.S. Poverty." Unpublished manuscript accessed at: https://www.census.gov/content/dam/Census/library/workingpapers/1997/demo/orshansky.pdf.

Fontenot, Kayla, Jessica Semega, and Melissa Kollar. 2018. "Income and Poverty in the United States: 2017." U.S. Census Bureau, Current Population Reports, P60-263, Washington, D.C.: U.S. Government Printing Office.

Fox, Liana. 2017. “The Supplemental Poverty Measure: 2016.” U.S. Census Report Number P60-261. At: https://www.census.gov/content/dam/Census/library/publications/2017/demo/ p60-261.pdf.

Glasmeier, Amy K. and Carey Ann Nadeau. 2018. "Living Wage Calculator: User Guide/Technical Notes," 2018 update. Unpublished manuscript, MIT. Accessed at: http://livingwage.mit.edu/articles/30-the-mit-living-wage-tooland-the-2018-redesign-and-update.

Glassman, Brian. 2017. "A Multidimensional Poverty Measure using the American Community Survey." U.S. Census Bureau Working Paper Number 2017-47. Accessed at: https://www.census.gov/content/dam/Census/library/workingpapers/2017/demo/SEHSD-WP2017-47.pdf.

Gordon, Linda and Felice Batlan, F. 2011. "The Legal history of the Aid to Dependent Children Program." Social Welfare History Project. Accessed at: http://socialwelfare.library.vcu.edu/public-welfare/aid-to-dependentchildren-the-legal-history/.

Gustafson, Kaaryn. 2012. Cheating Welfare: Public Assistance and the Criminalization of Poverty. New York, NY: NYU Press

Kimberlin, Sara and Amy Rose. 2017. "Making Ends Meet: How Much Does It Cost to Support a Family in California?" California Budget \& Policy Center report. At: https://calbudgetcenter.org/wp-content/uploads/Making-EndsMeet-12072017.pdf.

Ko, Janice, Alicia Simba, Madison Alits, Francesca Carlos, Rayanne Farhat, Gaby Ferrell, Aurbi Juhasz, Christina Saint Louis, Fatima Koli and Premilla Nadasen. 2018. "The State of Women's Economic Security In Mississippi 2018," Produced for the Mississippi Low Income Child Care Initiative, access at: https://mssemester.wordpress.com/index/. 
Nadasen, Premilla. 2005. Welfare Warriors: The Welfare Rights Movement in the United States, New York: Routledge.

National Research Council. 1995. Measuring Poverty: A New Approach.

Washington, DC: The National Academies Press. https://doi.org/10.17226/4759.

Mason, C. Nicole. 2013. "Economic Security and Well-Being Index for Women In New York City." Unpublished report, The New York Women's Foundation. At: https://www.nywf.org/wp-content/uploads/2017/02/NewYork-Womens-Foundation-Report.pdf.

Neckerman, Kathryn M., Irwin Garfinkel, Julien O. Teitler, Jane Waldfogel, and Christopher Wimer. 2016. "Beyond Income Poverty: Measuring Disadvantage in Terms of Material Hardship and Health." Academic Pediatrics 16 (3, Supplement): S52-S59. https://doi.org/10.1016/j.acap.2016.01.015.

Pearce, Diana. 2010. "The Self-Sufficiency Standard for New York City 2010." Unpublished report, University of Washington School of Social Work, Center for Women's Welfare. At: http://selfsufficiencystandard.org/sites/default/files/selfsuff/docs/NYC2010.p df.

Raphael, Steven and Michael A. Stoll. 2002 "Modest Progress: The Narrowing Spatial Mismatch between Blacks and Jobs in the 1990s." In Redefining Urban and Suburban America: Evidence from Census 2000 vol. 3, edited by A. Berube, B. Katz, and R.E. Lang, 119-42. Washington, DC: The Brookings Institution.

Roberts, Dorothy. 1998. Killing the Black Body: Race, Reproduction, and the Meaning of Liberty. New York, NY: Vintage

Robeyns, Ingrid. 2016. "The Capability Approach.” In The Stanford Encyclopedia of Philosophy, edited by E. Zalta, accessed at: https://plato.stanford.edu/archives/win2016/entries/capability-approach/. Sanders, Crystal. 2016. A Chance for Change: Head Start and Mississippi's Black Freedom Struggle. Chapel Hill, NC: University of North Carolina Press. https://doi.org/10.5149/northcarolina/9781469627809.001.0001.

Shaefer, H. Luke, and Kathryn Edin. 2012. "Extreme Poverty in the United States, 1996 to 2011." National Poverty Center Policy Brief no. 28

(February). Accessed 31 October 2018. http://www.npc.umich.edu/publications/policy_briefs/brief28/policybrief28.p df.

Semega, Jessica L., Kayla R. Fontenot and Melissa A. Kollar. 2017. "Income and Poverty in the United States: 2016." U.S. Census Report Number P60259. At: https://www.census.gov/library/publications/2017/demo/p60259.html. 
Sen, Amartya. 1999. Development as Freedom, New York: Oxford University Press.

Sen, Amartya. 2009. The Idea of Justice, Cambridge, MA: Harvard University Press.

Smeeding, Timothy M. 2017. "Poverty Measurement." in The Oxford Handbook of the Social Science of Poverty, edited by D. Brady and L. Burton, New York: Oxford University Press. https://doi.org/10.1093/oxfordhb/9780199914050.013.3.

U.S. President. 1964. Economic Report of the President. Washington: GPO.

Wood, B. Dan, Chris T. Owens, and Brandy M. Durham. 2005. "Presidential Rhetoric and the Economy." Journal of Politics 67 (3): 627-45. https://doi.org/10.1111/j.1468-2508.2005.00332.x.

Woods, Clyde A. 2017. Development Arrested: the Blues and Plantation Power in the Mississippi Delta. New York, NY: Verso 